Research Paper

\title{
Combination Analysis in Genetic Polymorphisms of Drug-Metabolizing Enzymes CYP1A2, CYP2C9, CYP2C19, CYP2D6 and CYP3A5 in the Japanese Population
}

Tomoko Ota, Yuka Kamada, Mariko Hayashida, Kyoko Iwao-Koizumi, Shigenori Murata, Kenji Kinoshita $^{\varpi}$

School of Pharmaceutical Sciences, Mukogawa Women's University, 11-68, Koshien Kyuban-Cho, Nishinomiya, Hyogo 663-8179, Japan.

$\triangle$ Corresponding author: Kenji Kinoshita, Address: School of Pharmaceutical Sciences, Mukogawa Women's University, 11-68 Koshien Kyuban-Cho Nishinomiya, Hyogo 663-8179, Japan. TEL: +81-798-45-9982 FAX: +81-798-41-2792 E-mail: kenji_k@mukogawa-u.ac.jp.

( ) Ivyspring International Publisher. This is an open-access article distributed under the terms of the Creative Commons License (http://creativecommons.org/ licenses/by-nc-nd/3.0/). Reproduction is permitted for personal, noncommercial use, provided that the article is in whole, unmodified, and properly cited.

Received: 2014.08.05; Accepted: 2014.11.03; Published: 2015.01.01

\begin{abstract}
The Cytochrome P450 is the major enzyme involved in drug metabolism. CYP enzymes are responsible for the metabolism of most clinically used drugs. Individual variability in CYP activity is one important factor that contributes to drug therapy failure. We have developed a new straightforward TaqMan PCR genotyping assay to investigate the prevalence of the most common allelic variants of polymorphic CYP enzymes CYP1A2, CYP2C9, CYP2C19, CYP2D6 and CYP3A5 in the Japanese population. Moreover, we focused on the combination of each genotype for clinical treatment. The genotype analysis identified a total of 139 out of 483 genotype combinations of five genes in the 1,003 Japanese subjects. According to our results, most of subjects seemed to require dose modification during clinical treatment. In the near future, modifications should be considered based on the individual patient genotype of each treatment.
\end{abstract}

Key words: Cytochrome P450, TaqMan-PCR, dried saliva, Japanese population, Genetic analysis.

\section{Introduction}

Cytochrome P450 (CYP) enzymes constitute the major metabolizing enzyme system in humans, and are responsible for the metabolism of exogenous compounds, including many drugs, carcinogens, mutagens and alcohols [1,2]. Generally, the CYP enzymes represent $70-80 \%$ of phase I metabolism and are responsible for the biotransformation of lipophilic drugs to polar metabolites, which can be excreted by the kidneys [3]. The human hepatic CYP system consists of more than 30 related isoenzymes with different, sometimes overlapping substrate specificities [4]. A major cause of inter-individual variability of drug pharmacokinetics is the genetic polymorphism of metabolizing enzymes [5]. In many cases, CYP polymorphism has a major variable affecting drug plasma concentration, drug detoxification, and drug activation in the case of a prodrug [6]. Several of the major genetic polymorphisms affecting drug-metabolizing enzyme activity of potential clinical relevance are those related to the CYP450 enzymes: CYP1A2, CYP2C9, CYP2C19, CYP2D6 and CYP3A5.

CYP1A2 is one of the drug-metabolizing enzymes of major importance, as it catalyzes the phase I metabolism of a broad range of different drugs, including caffeine, lidocaine, theophylline, and propranolol $[7,8]$. CYP2C9 is involved in the metabolism of many clinically important drugs, including (S)-warfarin, losartan and phenytoin [9, 10]. Ethnic distributions of the CYP2C9 polymorphisms are clinically significant in anticoagulation therapy because 
CYP2C9 is the major P450 that inactivates the active $S$-enantiomer of warfarin [6]. CYP2C19 catalyzes the metabolism of many commonly used drugs, including omeprazole [11], phenytoin [12], and diazepam [13]. Most poor metabolization of CYP2C19 is attributable to the CYP2C19*2 and *3 alleles. Proton pump inhibitors, which are used for the treatment of gastric acid-related disease, are mainly metabolized by CYP2C19 in the liver [14]. CYP2D6 is responsible for the metabolism of approximately 20 to $25 \%$ of all marketed drugs [15]. More than 50 clinically important drug substrates of CYP2D6 have been identified [16], including tamoxifen [17], codeine [18] and dextromethorphan [19]. CYP2D6 is highly polymorphic. Variant alleles of CYP2D6 are classified on the basis of enzymatic activities. CYP2D6 has complex alleles such as CYP2D $6^{*} 36-{ }^{*} 10$ Tandem-type [20]. However, these two alleles * 10 and $* 5$ are considered to be sufficient as a minimum genetic information before personalizing medication based on genotype $[21,22]$. CYP2D $6^{*} 5$ has been reported previously [23]. CYP3A4/5 metabolize a broad range of structurally diverse therapeutic compounds, including tacrolimus $[24,25]$ and midazolam [26]. Since the minor allele frequencies of CYP3A4 SNPs are low in the Japanese population, we focused on the CYP3A5 gene. The CYP $3 A 5^{*} 3$ allele is the most frequently occurring allele of CYP3A5 and contains a single nucleotide polymorphism (SNP) that introduces a frame shift during translation, resulting in a truncated, non-functional protein [27].

The previous study reported on the enzyme activities and genotype associations of CYP1A2, CYP2C9, CYP2C19, CYP2D6, CYP2E1, and CYP3A4/5 to evaluate the effect among native Japanese, Chinese, Koreans, and Caucasians, using caffeine, midazolam, omeplazole, dextromethorphan, chlozoxazone and losartan as panels of specific CYP probe substrates [28]. Furthermore, other studies have reported on population and combination analysis of genetic polymorphism for CYP genes in Greek subjects [29] and Chinese subjects [30].

The purpose of the present study was to investigate the prevalence of the most common allelic variants of CYP1A2*1C, CYP2C9*3, CYP2C19*2, *3, CYP2D $6^{*} 10$ and CYP3A5*3, as well as the number and frequencies of individuals with genotypes predictive of extensive metabolizers (EM), poor metabolizers $(\mathrm{PM})$, intermediate metabolizers (IM), and the phenotypic status in a representative sample of the Japanese population. Although a large number of studies have been carried out on each genotype analysis, no study has ever attempted to analyze the combination of many genotypes. Therefore we focused on the combination of each genotype for clinical treatment.
Genetic variation in drug metabolism could cause therapeutic failures, adverse drug effects or even fatal drug intoxications [15]. The development of molecular methods for genotyping could provide researchers with the tools to pinpoint the genetic differences between individuals and in some cases give the prescribing clinician a means to improve the pharmacotherapeutic regimen of each patient on the basis of the genetic profile, thus reducing harmful side-effects or inadequate drug response [29]. Despite the advantages of CYP genotyping in drug therapy, currently it is rarely performed in clinical practice. Our results contribute to the overall knowledge of the Japanese distribution of the genetically controlled metabolism of several important drugs and may help in the optimization of pharmacotherapy in ethnically Japanese subjects.

\section{Materials and methods}

Human Genomic DNA Samples: A total of 1,017 non-related Japanese subjects participated in each genotype determination of the allele frequencies of CYP1A2*1C, CYP2C9*3, CYP2C19*2, CYP2C19*3, $C Y P 2 D 6^{*} 10$ and $C Y P 3 A 5^{*}$. The saliva of the healthy Japanese volunteers was analyzed by TaqMan PCR (Applied Biosystems, Foster City, CA) assay. The Medical Ethics Committee of Mukogawa Women's University approved the study protocol. Informed consent was obtained from all subjects. The subjects were asked to rub their inner cheek surfaces against their teeth and to collect saliva in small plastic tubes. Then ca. $50 \mu \mathrm{L}$ of the saliva were put on pieces of water-soluble paper (Nippon Paper Papylia Co., Ltd., Mishima Dissolve Paper, 60MDP), and were dried for one hour at room temperature.

Detection of the CYP genotyping by TaqMan PCR assay: SNPs of each gene were genotyped by TaqMan assay on ABI 7300 Real Time PCR System (Applied Biosystems). The TaqMan assay was performed with a $20 \mu \mathrm{L}$ reaction volume and consisted of $10 \mu \mathrm{L}$ of Thunderbird probe qPCR Mix (TOYOBO), 0.4 $\mu \mathrm{L}$ of $50 \times \mathrm{ROX}$ reference dye (TOYOBO), $1 \mu \mathrm{L}$ of 20xeach TaqMan probe \& each Primer Mix, $2 \mu \mathrm{L}$ of $2 \times$ PCR Buffer for KOD FX Neo (TOYOBO), and $6.6 \mu \mathrm{L}$ of distilled water. The dried saliva was punched with a $1.2 \mathrm{~mm}$ diameter disk and put into the reaction mixture directly without DNA extraction. The thermal cycling process was performed according to the Applied Biosystems PCR conditions; 2 min at $50^{\circ} \mathrm{C}, 10$ min at $95^{\circ} \mathrm{C}, 40$ cycles of denaturation at $95^{\circ} \mathrm{C}$ for $15 \mathrm{~s}$, and annealing and extension at $60^{\circ} \mathrm{C}$ for $1 \mathrm{~min}$. The results were analyzed by ABI Prism 7300 SDS software. TaqMan probe assay IDs indicate that CYP1A2*1C: C_15859191_30, CYP2C9*3: C__27104892_10, CYP2C19*2: C_25986767_70, 
CYP2C19*3: C_27861809_10, CYP2D6*10: C_11484460_40, CYP3A5*3: C_26201809_30.

Method validation: The TaqMan assay was validated for system accuracy. The method validation was performed by the PCR-RFLP method using 219 samples. The PCR-RFLP protocols were shown in Supplementary Material: Table S1.

\section{Results and discussion}

Pharmacogenetic research has gained enormous momentum, with recent advances in molecular genetics and genome sequencing [31]. CYP enzymes metabolize more than $80 \%$ of drugs used in clinical settings [32]. Since five $C Y P$ genes, $C Y P 1 A 2, C Y P 2 C 9$, CYP2C19, CYP2D6 and CYP3A5 are medically significant, genotyping them could help medical treatment and optimization of drug therapy. In particular, most Japanese have mutations in these genes compared to Caucasians and it is already known that deficiencies of these genes may result in a need for dose adjustment. Genetic variation in drug metabolism can lead to therapeutic failures, adverse drug effects or even fatal drug intoxications [15].

The allele frequencies of the analyzed five genes were shown in Table 1 . These results gave us a similar distribution to the previous report [28]. It appears that the frequencies of these alleles in Japanese individuals are more polymorphic than in Caucasian individuals. Deviations from Hardy-Weinberg equilibrium were not statistically significant in the individual polymorphisms except for CYP2D $6{ }^{*} 10$ (CYP1A2; $\chi^{2}=0.42$, CYP2C $; \chi^{2}=0.76$, CYP2C19*2; $\chi^{2}=1.64$, CYP2C19*3; $\chi^{2}$ $=0.61$, CYP2D6; $\chi^{2}=55.89$, CYP3A5; $\chi^{2}=0.35, d f=1, P>$ $0.05)$. The genotype frequency of $C Y P 2 D 6^{*} 10$ was not in Hardy-Weinberg equilibrium, partly because the extreme polymorphisms of CYP2D6 gene, such as deletions and duplications, had been observed in the Japanese population $[17,20]$.

Table 1. Allele frequencies of CYPIA2, CYP2C9, CYP2C19, CYP2D6 and CYP3A5 $(\mathrm{n}=1017)$.

\begin{tabular}{|c|c|c|c|c|}
\hline Gene & Variant allele & This study & Japanese 28$)$ & Caucasian 28 \\
\hline$\overline{C Y P 1 A 2}$ & ${ }^{*} 1 \mathrm{C}$ & 0.234 & 0.319 & $0.010^{a}$ \\
\hline СYP2C9 & $* 3$ & 0.027 & 0.035 & $0.056^{a}$ \\
\hline \multirow[t]{2}{*}{ CYP2C19 } & $* 2$ & 0.295 & 0.345 & $0.136^{\mathrm{a}}$ \\
\hline & $* 3$ & 0.111 & 0.090 & $0.000^{\mathrm{a}}$ \\
\hline CYP2D6 & ${ }^{*} 10$ & 0.427 & 0.435 & $0.196^{a}$ \\
\hline СУР3А5 & $* 3$ & 0.762 & 0.780 & $0.955^{\mathrm{a}}$ \\
\hline
\end{tabular}

a Significantly different $(\mathrm{P}<0.05)$ mean allelic frequency compared with this study mean (Pearson's chi-square test).
The results of the TaqMan assay were completely consistent with those of the PCR-RFLP method (data not shown). The high accuracy of the results of the two different experiments proves that the TaqMan PCR assay was a simple and reliable genotyping method. Since we used a sample of dried saliva on water-soluble papers, we did not require DNA extraction and it was possible to put the sample directly into the reaction tubes [33]. Furthermore, this simple sampling method can minimize contaminants during the experiment.

The genotype distributions of five genes were shown in Table 2. None of these subjects was found to be homozygous for the CYP2C9*3 allele. The fourteen subjects could not define CYP2D6 genotype. The polymorphism of these subjects seems to be homozygous for $C Y P 2 D 6 * 5$, because this polymorphism is the deletion mutant. The previous reports suggested that the CYP2D6*5 allele was about 6\% [34]. The CYP2D ${ }^{*} 1 /{ }^{*} 5$ and ${ }^{*} 5 /{ }^{*} 10$ were included in ${ }^{*} 1 /{ }^{*} 1$ and ${ }^{*} 10 /{ }^{*} 10$, respectively. In the future, detailed analysis of CYP2D6*5 genotype will have to be carried out using our newly developed long PCR method [23].

Table 2. Genotype frequencies of CYPIA2, CYP2C9, CYP2CI9, CYP2D6 and CYP3A5 in the Japanese population $(n=1017)$.

\begin{tabular}{|c|c|c|c|c|}
\hline Gene & Genotypes & Phenotypes & $\begin{array}{l}\text { Number of } \\
\text { subjects }\end{array}$ & $\begin{array}{l}\text { Observed fre- } \\
\text { quency }(\%)\end{array}$ \\
\hline \multirow[t]{3}{*}{ CYP1A2 } & ${ }^{*} 1 A /{ }^{*} 1 A$ & EM & 593 & 58.3 \\
\hline & ${ }^{*} 1 \mathrm{~A} /{ }^{*} 1 \mathrm{C}$ & IM & 372 & 36.6 \\
\hline & ${ }^{*} 1 C /{ }^{*} 1 C$ & PM & 52 & 5.1 \\
\hline \multirow[t]{3}{*}{ CYP2C9 } & ${ }^{*} 1 /{ }^{*} 1$ & EM & 963 & 94.7 \\
\hline & $* 1 / * 3$ & IM & 54 & 5.3 \\
\hline & $* 3 / * 3$ & PM & 0 & 0 \\
\hline \multirow[t]{6}{*}{ CYP2C19 } & ${ }^{*} 1 /{ }^{*} 1$ & EM & 345 & 33.9 \\
\hline & ${ }^{*} 1 /{ }^{*} 2$ & IM & 377 & 37.1 \\
\hline & $* 1 / * 3$ & IM & 142 & 14.0 \\
\hline & $* 2 / * 2$ & PM & 80 & 7.9 \\
\hline & $* 2 / 3$ & PM & 63 & 6.2 \\
\hline & $* 3 / * 3$ & PM & 10 & 1.0 \\
\hline \multirow[t]{4}{*}{ CYP2D6 } & ${ }^{*} 1 /{ }^{*} 1$ & EM & 387 & 38.1 \\
\hline & ${ }^{*} 1 /{ }^{*} 10$ & IM & 375 & 36.9 \\
\hline & ${ }^{*} 10{ }^{*} 10$ & IM & 241 & 23.7 \\
\hline & Undefined & & 14 & 1.4 \\
\hline \multirow[t]{3}{*}{ СУРЗА5 } & ${ }^{*} 1 /{ }^{*} 1$ & EM & 61 & 6.0 \\
\hline & $* 1 / * 3$ & IM & 362 & 35.6 \\
\hline & $* 3 / * 3$ & PM & 594 & 58.4 \\
\hline
\end{tabular}

In general, the dosage of the drug would be in accordance with the mode values of the genotype, which are CYP1A2* $1 A{ }^{*} 1 A, \quad C Y P 2 C{ }^{*} 1 /{ }^{*} 1$, CYP2C19*1/*2, CYP2D $6^{*} 1 /{ }^{*} 1$ and CYP3A5*3/3, in each drug metabolic enzyme. However, the dosage seems to be set and does not appear to produce ad- 
verse effects in clinical studies. In other words, most Japanese have be administered under lower recommended dosage of drugs. We focused on the combination of each genotype for clinical treatment, because a large number of studies have been performed on each genotype analysis, and no study has ever attempted to analyze the combination of many genotypes. The genotype analysis identified a total of 139 out of 483 genotype combinations of five genes in the 1,003 Japanese subjects (except for CYP2D6 undefined fourteen subjects), which is shown in Supplementary Material: Table S2. Most of these combinations appeared in less than $1 \%$ of all samples. The thirty combinations with frequencies greater than or equal to $1 \%$ were used as a focus group, making up $68.0 \%$ of all samples shown in Table 3 . The highest frequency was $5.1 \%$. These results suggest that there are varieties of combinations in the Japanese populations. The dose modifications should be considered based on individual patient genotype for clinical treatment. Moreover, the genetic analysis of these five CYP genes would be very helpful for drug treatment in clinical studies.

Table 3. The combined genotype frequency of CYPIA2, CYP2C9, CYP2C19, CYP2D6 and CYP3A5 in the Japanese population.

\begin{tabular}{|c|c|c|c|c|c|c|c|}
\hline \multicolumn{8}{|c|}{ Genotype } \\
\hline No. & CYP1A2 & CYP2C9 & CYP2C19 & CYP2D6 & СУРЗА5 & Subject & $\%$ \\
\hline 1 & ${ }^{*} 1 A /{ }^{*} 1 A$ & ${ }^{*} 1 /{ }^{*} 1$ & ${ }^{*} 1 /{ }^{*} 1$ & ${ }^{*} 1 /{ }^{*} 1$ & $* 1 / * 3$ & 33 & $3.3 \%$ \\
\hline 2 & ${ }^{*} 1 A /{ }^{*} 1 A$ & ${ }^{*} 1 /{ }^{*} 1$ & ${ }^{*} 1 /{ }^{*} 1$ & ${ }^{*} 1 /{ }^{*} 1$ & $* 3 / * 3$ & 44 & $4.4 \%$ \\
\hline 3 & ${ }^{*} 1 A /{ }^{*} 1 A$ & ${ }^{*} 1 /{ }^{*} 1$ & ${ }^{*} 1 /{ }^{*} 1$ & ${ }^{*} 1 /{ }^{*} 10$ & $* 1 / * 3$ & 23 & $2.3 \%$ \\
\hline 4 & ${ }^{*} 1 A /{ }^{*} 1 A$ & ${ }^{*} 1 /{ }^{*} 1$ & ${ }^{*} 1 /{ }^{*} 1$ & ${ }^{*} 1 /{ }^{*} 10$ & $* 3 / * 3$ & 25 & $2.5 \%$ \\
\hline 5 & ${ }^{*} 1 A /{ }^{*} 1 A$ & ${ }^{*} 1 /{ }^{*} 1$ & ${ }^{*} 1 /{ }^{*} 1$ & ${ }^{*} 10 /{ }^{*} 10$ & ${ }^{*} 1 / * 3$ & 17 & $1.7 \%$ \\
\hline 6 & ${ }^{*} 1 A /{ }^{*} 1 A$ & ${ }^{*} 1 /{ }^{*} 1$ & ${ }^{*} 1 /{ }^{*} 1$ & ${ }^{*} 10 /{ }^{*} 10$ & $* 3 / * 3$ & 25 & $2.5 \%$ \\
\hline 7 & ${ }^{*} 1 A /{ }^{*} 1 A$ & ${ }^{*} 1 /{ }^{*} 1$ & ${ }^{*} 1 /{ }^{*} 2$ & ${ }^{*} 1 /{ }^{*} 1$ & ${ }^{*} 1 /{ }^{*} 3$ & 35 & $3.5 \%$ \\
\hline 8 & ${ }^{*} 1 A /{ }^{*} 1 A$ & ${ }^{*} 1 /{ }^{*} 1$ & ${ }^{*} 1 /{ }^{*} 2$ & ${ }^{*} 1 /{ }^{*} 1$ & $* 3 / * 3$ & 37 & $3.7 \%$ \\
\hline 9 & ${ }^{*} 1 A /{ }^{*} 1 A$ & ${ }^{*} 1 /{ }^{*} 1$ & ${ }^{*} 1 /{ }^{*} 2$ & ${ }^{*} 1 /{ }^{*} 10$ & ${ }^{*} 1 /{ }^{* 3}$ & 27 & $2.7 \%$ \\
\hline 10 & ${ }^{*} 1 A /{ }^{*} 1 A$ & ${ }^{*} 1 /{ }^{*} 1$ & ${ }^{*} 1 /{ }^{*} 2$ & ${ }^{*} 1 /{ }^{*} 10$ & $* 3 / * 3$ & 51 & $5.1 \%$ \\
\hline 11 & ${ }^{*} 1 A /{ }^{*} 1 A$ & ${ }^{*} 1 /{ }^{*} 1$ & ${ }^{*} 1 /{ }^{*} 2$ & ${ }^{*} 10 /{ }^{*} 10$ & $* 1 / * 3$ & 18 & $1.8 \%$ \\
\hline 12 & ${ }^{*} 1 A /{ }^{*} 1 A$ & ${ }^{*} 1 /{ }^{*} 1$ & ${ }^{*} 1 /{ }^{*} 2$ & ${ }^{*} 10 /{ }^{*} 10$ & $* 3 / * 3$ & 30 & $3.0 \%$ \\
\hline 13 & ${ }^{*} 1 A /{ }^{*} 1 A$ & ${ }^{*} 1 /{ }^{*} 1$ & ${ }^{*} 1 / * 3$ & ${ }^{*} 1 /{ }^{*} 1$ & $* 3 / * 3$ & 21 & $2.1 \%$ \\
\hline 14 & ${ }^{*} 1 A /{ }^{*} 1 A$ & ${ }^{*} 1 /{ }^{*} 1$ & $* 1 / * 3$ & ${ }^{*} 1 /{ }^{*} 10$ & $* 1 / * 3$ & 11 & $1.1 \%$ \\
\hline 15 & ${ }^{*} 1 A /{ }^{*} 1 A$ & ${ }^{*} 1 /{ }^{*} 1$ & $* 1 / * 3$ & ${ }^{*} 1 /{ }^{*} 10$ & $* 3 / * 3$ & 17 & $1.7 \%$ \\
\hline 16 & ${ }^{*} 1 A /{ }^{*} 1 A$ & ${ }^{*} 1 /{ }^{*} 1$ & $* 1 / * 3$ & ${ }^{*} 10 /{ }^{*} 10$ & $* 3 / * 3$ & 10 & $1.0 \%$ \\
\hline 17 & ${ }^{*} 1 A /{ }^{*} 1 A$ & ${ }^{*} 1 /{ }^{*}$ & $* 2 / * 2$ & ${ }^{*} 1 /{ }^{*} 1$ & $* 3 / * 3$ & 11 & $1.1 \%$ \\
\hline 18 & ${ }^{*} 1 A /{ }^{*} 1 A$ & ${ }^{*} 1 /{ }^{*} 1$ & $* 2 / * 2$ & ${ }^{*} 1 /{ }^{*} 10$ & $* 3 / * 3$ & 11 & $1.1 \%$ \\
\hline 19 & ${ }^{*} 1 A /{ }^{*} 1 C$ & ${ }^{*} 1 /{ }^{*} 1$ & ${ }^{*} 1 /{ }^{*} 1$ & ${ }^{*} 1 /{ }^{*} 1$ & $* 1 / * 3$ & 14 & $1.4 \%$ \\
\hline 20 & ${ }^{*} 1 A /{ }^{*} 1 C$ & ${ }^{*} 1 /{ }^{*} 1$ & ${ }^{*} 1 /{ }^{*} 1$ & ${ }^{*} 1 /{ }^{*} 1$ & $* 3 / * 3$ & 37 & $3.7 \%$ \\
\hline 21 & ${ }^{*} 1 A /{ }^{*} 1 C$ & ${ }^{*} 1 /{ }^{*} 1$ & ${ }^{*} 1 /{ }^{*} 1$ & ${ }^{*} 1 /{ }^{*} 10$ & ${ }^{*} 1 / * 3$ & 13 & $1.3 \%$ \\
\hline 22 & ${ }^{*} 1 A /{ }^{*} 1 C$ & ${ }^{*} 1 /{ }^{*} 1$ & ${ }^{*} 1 /{ }^{*} 1$ & ${ }^{*} 1 /{ }^{*} 10$ & $* 3 / * 3$ & 27 & $2.7 \%$ \\
\hline 23 & ${ }^{*} 1 A /{ }^{*} 1 C$ & ${ }^{*} 1 /{ }^{*} 1$ & ${ }^{*} 1 /{ }^{*} 1$ & ${ }^{*} 10 /{ }^{*} 10$ & $* 3 / * 3$ & 12 & $1.2 \%$ \\
\hline 24 & ${ }^{*} 1 A /{ }^{*} 1 C$ & ${ }^{*} 1 /{ }^{*} 1$ & ${ }^{*} 1 /{ }^{*} 2$ & ${ }^{*} 1 /{ }^{*} 1$ & ${ }^{*} 1 / * 3$ & 11 & $1.1 \%$ \\
\hline 25 & ${ }^{*} 1 A /{ }^{*} 1 C$ & ${ }^{*} 1 /{ }^{*} 1$ & ${ }^{*} 1 /{ }^{*} 2$ & ${ }^{*} 1 /{ }^{* 1}$ & $* 3 / * 3$ & 29 & $2.9 \%$ \\
\hline 26 & ${ }^{*} 1 A /{ }^{*} 1 C$ & ${ }^{*} 1 /{ }^{*} 1$ & ${ }^{*} 1 /{ }^{*} 2$ & ${ }^{*} 1 /{ }^{*} 10$ & ${ }^{*} 1 /{ }^{*} 3$ & 18 & $1.8 \%$ \\
\hline 27 & ${ }^{*} 1 A /{ }^{*} 1 C$ & ${ }^{*} 1 /{ }^{*} 1$ & ${ }^{*} 1 /{ }^{*} 2$ & ${ }^{*} 1 /{ }^{*} 10$ & $* 3 / * 3$ & 26 & $2.6 \%$ \\
\hline 28 & ${ }^{*} 1 A /{ }^{*} 1 C$ & ${ }^{*} 1 /{ }^{*} 1$ & ${ }^{*} 1 /{ }^{*} 2$ & ${ }^{*} 10 /{ }^{*} 10$ & $* 1 / * 3$ & 10 & $1.0 \%$ \\
\hline 29 & ${ }^{*} 1 A /{ }^{*} 1 C$ & ${ }^{*} 1 /{ }^{*} 1$ & ${ }^{*} 1 /{ }^{*} 2$ & ${ }^{*} 10 /{ }^{*} 10$ & $* 3 / * 3$ & 27 & $2.7 \%$ \\
\hline 30 & ${ }^{*} 1 A /{ }^{*} 1 C$ & ${ }^{*} 1 /{ }^{*} 1$ & $* 1 / * 3$ & ${ }^{*} 1 /{ }^{*} 10$ & $* 3 / * 3$ & 12 & $1.2 \%$ \\
\hline total & & & & & & 682 & $68.0 \%$ \\
\hline
\end{tabular}

Our result indicated 5\% PM $\left({ }^{*} 1 C /{ }^{*} 1 C\right)$ and $58 \%$ EM $\left({ }^{*} 1 A /{ }^{*} 1 A\right)$ for $C Y P 1 A 2$, and indicated that these subjects require either dose increments or dose reductions. Nakajima et al. reported that the point mutation of $C Y P 1 A 2 * 1 C$ caused a significant decrease of CYP1A2 activity measured by the rate of caffeine 3-demethylation in Japanese smokers [35]. CYP2C9*2 and $\mathrm{CYP} 2 \mathrm{C} 9 * 3$, the two most common variant alleles, exhibit largely reduced enzymatic activities. The Japanese subjects with the CYP2C9*1/*3 and CYP2C $9 * 3 * 3$ genotypes have lower warfarin doses than those with the CYP2C ${ }^{*} 1 /{ }^{*} 1$ genotype [36]. Our result indicated $5.3 \% \mathrm{IM}\left({ }^{*} 1{ }^{*} 3\right)$ for $C Y P 2 C 9$, and indicated that these subjects would require dose modifications.

For the CYP2C19 gene, there were many reports on the association between genes and clinical doses. Furuta et al. have reported that cure rates by lansoprazole therapy were $84.6 \%$ in PMs, $67.9 \%$ in IMs, and $45.8 \%$ in EMs [11]. The report also indicated that the mean values for the areas under the plasma - a concentration-time curve are about 13 times as high as those of the EM group. These clinical data would be useful for drug therapy in future studies. For lansoprazole therapy, our results indicated IM $\left({ }^{*} 1 /{ }^{*} 2,{ }^{*} 1 /{ }^{*} 3\right)$ and EM $\left({ }^{*} 1 /{ }^{*} 1\right)$ for $C Y P 2 C 19$, and indicated that these subjects required dose modifications.

According to the previous report with Tamoxifen therapy, the patients who have one or no normal allele of CYP2D6 required increased dose adjustment [17]. Since tamoxifen is a pro-drug, it is impossible to achieve the expected effect on a patient who has a ${ }^{*} 10$ allele. The $60.5 \%$ subjects $\left({ }^{*} 1 /{ }^{*} 10,{ }^{*} 10 /{ }^{*} 10\right)$ may require dosage adjustment in Japanese subjects for the CYP2D6 gene.

In our study, the CYP3A5*3 allele was found in abundance in the Japanese population with an indicated $76.2 \%$. Tacrolimus has a low therapeutic index with a wide range of side effects and large interindividual variability in its pharmacokinetics, particularly in the dose required to reach target trough blood concentrations, thus necessitating routine therapeutic drug monitoring in clinical practice [6]. Interestingly, Tsuchiya et al. reported that the CYP3A5*1 allele required a higher daily tacrolimus dose as compared to those of the CYP3A5*3/*3 genotype in kidney transplant recipients [37]. According to our results, $41.6 \%$ EM and IM $\left({ }^{*} 1 /{ }^{*} 1,{ }^{*} 1 /{ }^{*} 3\right)$ subjects would require dose adjustment or change of drug in Japanese subjects. Although a few attempts have been made with CYP3A5, it would be valuable to examine the subjects more closely in clinical settings.

This study is the first to investigate a population data that includes more than a thousand subjects and the combined genotypes of five important genes, 
which were $C Y P$ genes, CYP1A2, CYP2C9, CYP2C19, $C Y P 2 D 6$ and CYP3A5, all highly polymorphic genes in the Japanese population. Prospective clinical trials that evaluate the utility of genotyping and individualized medicine are critical in guiding clinical practice of individualized drug therapy [6].

Molecular genetic analysis could open new doors for targeted drug development and drug regulation to promote effective, safe, and cost-effective individualized drug therapy. Further prospective studies, showing a direct correlation between predictive genotyping and improvement of drug efficacy, could lead to the establishment of $C Y P$ genotyping [2]. If we knew our genotype information before treatment started, it would be possible to predict the severe side effects in clinical treatment. In medical settings, we expect the pharmacist to be able to design drug doses in consideration of the genotypes, on the grounds that the pharmacist is an expert in drugs. In order to propose the most appropriate structure for education programs for pharmacy students, it is vital that further research and development take place. This study has sought to spearhead such research and development.

\section{Supplementary Material}

Tables S1 - S2. http://www.medsci.org/v12p0078s1.pdf

\section{Competing Interests}

The authors have declared that no competing interest exists.

\section{References}

1. Rochat B. Role of Cytochrome P450 Activity in the Fate of Anticancer Agents and in Drug Resistance Focus on Tamoxifen, Paclitaxel and Imatinib Metabolism. Clin Pharmacokinet. 2005; 44:349-366.

2. van der Weide J, Hinrichs JW. The Influence of Cytochrome P450 Pharmacogenetics on Disposition of Common Antidepressant and Antipsychotic Medications. Clin Biochem Rev. 2006; 27:7-25.

3. Evans WE, Relling MV. Pharmacogenomics: Translating Functional Genomics into Rational Therapeutics. Science. 1999; 286:487-491.

4. van der Weide J, Steijns LS. Cytochrome P450 enzyme system: genetic polymorphisms and impact on clinical pharmacology. Ann Clin Biochem. 1999; 36:722-729.

5. Ingelman-Sundberg M. Pharmacogenetics of cytochrome P450 and its applications in drug therapy: the past, present and future. Trends Pharmacol Sci. 2004; 25:193-200.

6. Ma Q, Lu AY. Pharmacogenetics, Pharmacogenomics, and Individualized Medicine. Pharmacol Rev. 2011; 63:437-459.

7. Zhou SF, Yang LP, Zhou ZW, et al. Insights into the Substrate Specificity, Inhibitors, Regulation, and Polymorphisms and the Clinical Impact of Human Cytochrome P450 1A2. The AAPS Journal. 2009; 11:481-494.

8. Backman JT, Karjalainen MJ, Neuvonen M, et al. Rofecoxib is a potent inhibitor of cytochrome P450 1A2: studies with tizanidine and caffeine in healthy subjects. Br J Clin Pharmacol. 2006; 62:345-357.

9. Yin T, Maekawa K, Kamide K, et al. Genetic Variations of CYP2C9 in 724 Japanese Individuals and Their Impact on the Antihypertensive Effects of Losartan. Hypertens Res. 2008; 31:1549-1557.

10. Lee CR, Goldstein JA, Pieper JA. Cytochrome P450 2C9 polymorphisms: a comprehensive review of the in-vitro and human data. Pharmacogenetics. 2002; 12:251-263.

11. Furuta T, Shirai N, Sugimoto M, et al. Infuluece of CYP2C19 Pharmacogenetic Polymorphism on Proton Pump Inhibitor-based Therapies. Drug Metab Pharmacokinet. 2005; 20:153-167.
12. Thorn CF, Whirl-Carrillo M, Leeder JS, et al. PharmGKB summary: phenytoin pathway. Pharmacogenet Genomics. 2012; 22:466-470.

13. Lee SJ. Clinical application of CYP2C19 pharmacogenetics toward more personalized medicine. Front Genet. 2013; 3:318.

14. Sistonen J, Fuselli S, Palo JU, et al. Pharmacogenetic variation at CYP2C9, CYP2C19, and CYP2D6 at global and microgeographic scales. Pharmacogenet Genomics. 2009; 19:170-179.

15. Ingelman-Sundberg M. Genetic polymorphisms of cytochrome P450 2D6 (CYP2D6): clinical consequences, evolutionary aspects and functional diversity. Pharmacogenomics J. 2005; 5:6-13.

16. Zanger UM, Raimundo S, Eichelbaum M. Cytochrome P450 2D6: overview and update on pharmacology, genetics, biochemistry. Naunyn-Schmiedeberg's Arch Pharmacol. 2004; 369:23-37.

17. Kiyotani $\mathrm{K}$, Mushiroda $\mathrm{T}$, Imamura $\mathrm{CK}$, et al. Dose-adjustment study of tamoxifen based on CYP2D6 genotypes in Japanese breast cancer patients. Breast Cancer Res Treat. 2012; 131:137-145.

18. Crews KR, Gaedigk A, Dunnenberger HM, et al. Clinical Pharmacogenetics Implementation Consortium (CPIC) Guidelines for Codeine Therapy in the Context of Cytochrome P450 2D6 (CYP2D6) Genotype. Clin Pharmacol Ther. 2012; 91:321-326.

19. Kiyotani $\mathrm{K}$, Shimizu M, Kumai $\mathrm{T}$, et al. Limited effects of frequent CYP2D $6 * 36-{ }^{*} 10$ tandem duplication allele on in vivo dextromethorphan metabolism in a Japanese population. Eur J Clin Pharmacol. 2010; 66:1065-1068.

20. Soyama A, Saito Y, Kubo T, et al. Sequence-based Analysis of the CYP2D6*36-CYP2D6*10 Tandem-type Arrangement, a Major CYP2D6*10 Haplotype in the Japanese Population. Drug Metab Pharmacokinet. 2006; 21:208-216.

21. Hosono N, Kato M, Kiyotani K, et al. CYP2D6 Genotyping for Functional-Gene Dosage Analysis by Allele Copy Number Detection. Cliinical Chemistry. 2009; 55:1546-1554.

22. Kiyotani K, Mushiroda T, Imamura CK, et al. Significant Effect of Polymorphisms in CYP2D6 and ABCC2 on Clinical Outcomes of Adjuvant Tamoxifen Therapy for Breast Cancer Patients. J Clin Oncol. 2010; 28:1287-1293.

23. Ota T, Hayashida M, Ishii M, et al. Long PCR-based genotyping for deleted CYP2D6 gene without DNA extraction. Drug Metab Pharmacokinet. 2014; 29:283-285.

24. Katsakiori PF, Papapetrou EP, Goumenos DS, et al. Tacrolimus and 3-hydroxy-3-methylglutaryl-coenzyme A reductase inhibitors: An interaction study in CYP3A5 non-expressors, renal transplant recipients. Indian J Pharmacol. 2011; 43:385-388.

25. $\mathrm{Li} \mathrm{L}, \mathrm{Li} \mathrm{CJ}$, Zheng $\mathrm{L}$, et al. Tacrolimus dosing in Chinese renal transplant recipients: a population-based pharmacogenetics study. Eur J Clin Pharmacol. 2011; 67:787-795

26. Miao J, Jin Y, Marunde RL, et al. Association of Genotypes of the CYP3A Cluster with Midazolam Disposition In Vivo. Pharmacogenomics J. 2009; 9:319-326.

27. Kuehl $\mathrm{P}$, Zhang J, Lin $\mathrm{Y}$, et al. Sequence diversity in CYP3A promoters and characterization of the genetic basis of polymorphic CYP3A5 expression. Nature genetics. 2001; 27:383-391.

28. Myrand SP, Sekiguchi K, Man MZ, et al. Pharmacokinetics/Genotype Associations for Major Cytochrome P450 Enzymes in Native and First- and Third-generation Japanese Populations: Comparison With Korean, Chinese, and Caucasian Populations. Clini Pharmacol Ther. 2008; 84:347-361.

29. Arvanitidis K, Ragia G, Iordanidou M, et al. Genetic polymorphisms of drug-metabolizing enzymes CYP2D6, CYP2C9, CYP2C19 and CYP3A5 in the Greek population. Fund Clin Pharmacol. 2007; 21:419-426.

30. Wu Z, Zhang X, Shen L, et al. A Systematically Combined Genotype and Functional Combination Analysis of CYP2E1, CYP2D6, CYP2C9, CYP2C19 in Different Geographic Areas of Mainland China - A Basis for Personalized Therapy. PLoS One. 2013; 8.

31. Wolf CR, Smith G, Smith RL. Science, medicine, and the future Pharmacogenetics. BMJ. 2000; 320:987-990.

32. Nebert DW, Russell DW. Clinical importance of the cytochromes P450. The Lancet. 2002; 360:1155-1162.

33. Hayashida M, Ota T, Ishii $M$, et al. Direct Detection of Single Nucleotide Polymorphism (SNP) by the TaqMan PCR assay using Dried Saliva on Water-soluble Paper and Hair-roots, without DNA Extraction. Anal Sci. 2014; 30:427-429.

34. Kubota T, Yamaura Y, Ohkawa N, et al. Frequencies of CYP2D6 mutant alleles in a normal Japanese population and metabolic activity of dextromethorphan O-demethylation in different CYP2D6 genotypes. Br J Clin Pharmacol. 2000; 50:31-34.

35. Nakajima M, Yokoi T, Mizutani M, et al. Genetic polymorphism in the 5'-flanking region of human CYP1A2 gene: effect on the CYP1A2 inducibility in humans. J Biochem. 1999; 125:803-808.

36. Takahashi $\mathrm{H}$, Echizen $\mathrm{H}$. Pharmacogenetics of $\mathrm{CYP} 2 \mathrm{C} 9$ and interindividual variability in anticoagulant response to warfarin. Pharmacogenomics J. 2003; 3:202-214.

37. Tsuchiya N, Satoh $\mathrm{S}$, Tada $\mathrm{H}$, et al. Influence of CYP3A5 and MDR1 (ABCB1) Polymorphisms on the Pharmacokinetics of Tacrolimus in Renal Transplant Recipients. Transplantation. 2004; 78:1182-1187. 